\title{
Academic Survival Skills for Urban Students
}

\author{
Frederick M. Hampton ${ }^{1}$ \\ ${ }^{1}$ Cleveland State University, Cleveland, USA \\ Correspondence: Frederick M. Hampton, Associate Professor of Education, Cleveland State University, Julka Hall, \\ 2485 Euclid Avenue, Cleveland, Ohio 44115, USA. Tel: 216-849-8797
}

Received: July 22, 2020

Accepted: August 26, 2020

Online Published: September 30, 2020

doi:10.5430/irhe.v5n3p1

URL: https://doi.org/10.5430/irhe.v5n3p1

\begin{abstract}
This article discusses specific attitudes, behaviors, and skills used by some urban students to greatly enhance their chances of experiencing academic success in school. Both qualitative and quantitative analyses demonstrate that regardless of students' socio-economic background or ethnicity and race, high achievement can become an expectation. The research found the most commonly shared attribute among academically successful urban students was their willingness to assume greater personal responsibility for their educational outcomes. This research supports the position that urban schools should incorporate the teaching and practice of these attitudes, behaviors, and skills into the daily curriculum as a mechanism for meaningful student achievement and personal growth.
\end{abstract}

Keywords: urban education, students, achievement, self-reliance, African-American, Hispanic

Survival skills are not rooted in what others can do for you, but in what you can do for yourself.

The Coronavirus, also known as COVID 19 caused nearly 100\% of public schools across the United States to be shut down in March of 2020. Although there was early hope of reopening, the schools remained closed for the duration of the academic year. This crisis led schools to scramble to find ways to continue to keep students engaged in relevant learning activities and course completion without the benefit of being in physical classrooms.

While there is no real substitute for in-class and hands-on teaching, schools that had made early investments in distance learning technology and training for both teachers and students fared far better during this time than those who had not. Many suburban schools had already incorporated and funded models such as "one-to-one technology" where each student is provided a personal laptop or similar device for use at both school and home. These districts had also established partnerships with local cable services to ensure that virtually every home had Internet access, even for free if necessary. In these cases, students were well-positioned to remain in continuous contact with their teachers and to be remotely provided instruction, materials, and feedback resulting in much less interrupted learning.

During this same period many urban districts, especially those primarily composed of African-American and Hispanic students saw meaningful instruction greatly reduced, and in some instances come to a screeching halt. The mass integration and utilization of instructional technology in these schools could at best be described as spotty. While urban educators fight valiantly to teach and fulfill the myriad needs of their students at school on a day-to-day basis, many of these districts found themselves ill-prepared or completely at a loss as to providing meaningful instruction to students from a distance.

As urban districts hurriedly shut down, a few schools rushed to make paper copies of worksheets to be distributed to students. Although the worksheets could provide continued practice in multiple subject areas, there was little expectation or requirement that the tasks be completed or that it would even be returned or graded. In other instances, there were hastily made, but short-lived plans for parents to come to school on a daily basis to pick up homework for their children. Oftentimes when efforts were made to provide students with laptops, weeks had already passed and there was no guarantee of Internet access in the home or that students were knowledgeable of relevant instructional applications. Teachers were commonly left directionless in terms of expectations for providing instruction to students, 
other than to be available for two hours per day. More often than not, the Coronavirus shutdown resulted in nearly three months of unfulfilled instructional time for urban students.

Students of color who attend schools in large metropolitan areas have struggled academically in even the best of times. Whether due to social, economic, political, or familial conditions, African-American and Hispanic students, in general, have always trailed their suburban and rural counterparts on all indicators of school success. Unfortunately, the Coronavirus shutdown has stalled any academic gains that may have been on the horizon.

By 2015 DeArmond et.al from The Center for Reinventing Public Education had already painted a stark picture of schooling in some of the nation's cities, particularly for low-income students and students of color. The study takes into account nine indicators around the health of public education - across all public schools in the cities - and does not separate traditional district schools from charter schools. Among the major findings were:

- Less than a third of the cities examined made gains in math or reading proficiency over the three-year study span relative to their state's performance.

- One in 4 students in 9th grade in 2009 did not graduate from high school in four years.

- Forty percent of schools across the cities that were in the bottom 5 percent in their state stayed there for three years.

- Less than 10 percent of urban high school students enrolled in advanced-math classes each year in 29 of the 50 cities.

- Less than 15 percent of urban high school students took the ACT/SAT in 30 of the 50 cities.

- Low-income students and students of color were less likely to enroll in high-scoring elementary and middle schools than those who were more affluent or were white.

- On average, 8 percent of students in the study cities were enrolled in "beat the odds" schools - those that got better results than demographically similar schools in the state.

- About a 14 percentage-point achievement gap existed between students who were eligible for free and reduced-price meals and those who were not.

- Black students were almost twice as likely to receive an out-of-school suspension as White students.

There is no single issue or cause that has led to the devastatingly poor academic outcomes of urban students over the years. But, there are seemingly endless and insurmountable conditions and circumstances that contribute to their failure. Students and teachers in urban schools have greater challenges to overcome in many areas compared to their suburban and rural counterparts. Studies by Hudley, (2013) pointed out that:

- Urban schools have larger enrollments, on average than suburban or rural schools at both the elementary and secondary levels.

- Urban teachers have fewer resources available to them and less control over their curriculum than teachers in other locations, as do teachers in urban high poverty schools compared with those in rural high poverty schools.

- Administrators of urban high poverty schools have more difficulty hiring teachers than their counterparts in most other schools.

- Teacher absenteeism, an indicator of morale, was more of a problem in urban schools than in suburban or rural schools, and in urban high poverty schools compared with rural high poverty schools.

- Student behavior problems were more common in urban schools than in other schools, particularly in the areas of student absenteeism, classroom discipline, weapons possession, and student pregnancy.

Hudley went on to state that the general education urban students receive in public schools is demonstrably insufficient to make them competitive with their more advantaged, middle, and upper-income peers. Specific examples include the emphasis placed on the importance of STEM careers for the future of our youth and our country. Mathematics classes in high-poverty high schools are twice as likely to be taught by a teacher with a credential other than mathematics as are mathematics classes at low-poverty high schools. Similarly, for science classes at high-poverty high schools, teachers are three times as likely to be credentialed in areas other than science as those who teach science at low-poverty high schools. 


\section{Which Urban Students Demonstrate Academic Survival Skills}

Even the most casually interested observer can broadly describe the reasons so many urban youths experience academic failure. Their explanations often include circumstances such as generational poverty, the devaluation of education, fragmented family structures, high unemployment rates, physically deteriorating schools, poorly funded districts, high rates of teen pregnancy, and neighborhoods with high rates of drug use and crime. Each of those conditions, if not collectively then individually, has likely inhibited the academic success of many urban youths. And, it is inarguable that those circumstances have existed for multiple generations. From a statistical perspective, the odds of any urban k-12 student receiving a fundamentally sound education that well prepares him or her with post-high school career options for upward social and economic mobility are relatively low.

Educators generally understand the rationale and conditions leading to urban school failure. But, we have yet to capitalize on and learn from the lives and stories of those urban students who overcome their environmental conditions to experience stellar academic success. Every year, some urban students survive devastating family, community, and school obstacles, then go on to graduate with honors and are well prepared to pursue intellectually challenging career options. A few of those students receive full academic scholarships to attend prestigious universities. Others acquire grade point averages (GPAs) and Scholastic Achievement Test (SAT) scores for traditional acceptance into colleges and universities. And still, some qualify for admittance into community colleges, the armed forces, and to pursue high paying skilled labor apprenticeships.

Almost everyone can think of a friend or an acquaintance that overcame tremendously difficult circumstances and became successful in a specific field. We have all heard of individuals who were born into poverty, attended failing schools, were raised by a single parent, and survived tough city streets. Yet those individuals went on to become some of our most admired citizens. How is this possible? What distinguishes one student from another when neither has familial, economic, or social advantages? Why does one inner-city student succeed in school while another fails, yet both are demographically similar?

Answers to those questions are highly complex and cannot be condensed into one easily digestible response. However, it is clear that urban youth who defy the odds of school failure and excel in their environment have mastered and use an array of academic survival techniques. Those techniques being the acquisition and application of specific attitudes, behaviors, and skills which greatly enhance the odds of school success. Certainly, every student regardless of race needs parental support, effective teachers, instructional materials and equipment, and district leadership to experience optimal academic achievement. But, since urban youth have more challenges in finding consistent access to those necessities, the self-reliance on academic survival skills often becomes the difference between school success and failure.

Over the decades, there are countless examples of urban youth who not only succeeded in school but soared into the outer stratosphere of academic success. Oftentimes, those students give credit to specific teachers or administrators who motivated and inspired them toward self-efficacy. There are untold numbers of urban youth who succeeded in school solely because their parents and grandparents refused to accept anything less than academic excellence from them. Unfortunately, an examination of achievement data over the past 30 years reveals those scenarios to be the exceptions rather than the rules.

Notwithstanding the lack of advantages currently available to urban students, those who do excel and distinguish themselves from their peers have learned to take advantage of all the supports and services that can be found in these environments. More importantly, they are either innately or overtly aware that they too must make great contributions to their own school success. It is important to note that the students who exhibit the highest academic performance in these environments are not necessarily those with the highest IQ's, but are the students who demonstrate that they are committed to learning and are willing to work for accomplishment.

\section{Identifying the Academic Survival Skills of Urban Students}

Research in this area began with a qualitative study entitled "The Seven Secrets of Successful Inner-City Students" (Hampton, 2008). That study examined the lives of five academically successful seniors from an inner-city high school in Cleveland, Ohio. The search for those students was conducted with the caveat that they had come from impoverished homes, were raised by only one parent, and that parent had no formal education beyond high school. Each of those students overcame tremendously difficult personal and family circumstances. None of the students had been involved with their fathers, all were on public assistance, one of the students had faced homelessness, and some others had been in the care of various extended family members. Some of the students had witnessed the effects of 
drugs on their remaining parent, at least one of the students had an imprisoned parent, and all lived in neighborhoods with high drug, crime, and gang activity.

Given those conditions however, all five of those students demonstrated high academic achievement and had mapped out promising post-high school careers. All those students had GPAs that ranged from 3.3 - 4.0. One student had received a full academic scholarship to attend a southern historically black college (HBCU) and another had received a partial academic scholarship to attend a different HBCU. Although the remaining three qualified for general college admission, two deferred entrance for military service and governmental funding for college, which was their long-term goal. The final student intended to enroll in community college to begin a nursing program.

After six months of weekly recorded interviews with the students and their teachers, and volumes of anecdotal records and details, seven themes or common characteristics among the students emerged which helped to explain their academic success. Although in varying degrees, they all shared specific characteristics in attitudes, behaviors, and skills related to successful learning and achievement. While none of the five students particularly regarded the others as friends, those seven characteristics emerged as the most common denominators defining their paths to academic achievement. Those attitudes, behaviors, and skills collectively became known as their Academic Survival Skills or Successful Learner Characteristics and were defined as follows:

1. Self-respect - The extent to which the student demonstrates a high regard for him or herself.

2. Command of Standard English - The extent to which the student demonstrates the desire and ability to routinely construct grammatically correct sentences and to pronounce words correctly.

3. Goal-setting ability - The extent to which the student demonstrates the ability to identify relevant short and long-term objectives leading to a desired outcome.

4. Self-motivation - The extent to which the student demonstrates the ability to push him or herself toward the accomplishment of relevant short and long-term objectives and goals.

5. Time management skills - The extent to which the student demonstrates the ability to plan, organize, schedule, and work on relevant tasks.

6. Consequence awareness - The extent to which the student demonstrates a concern for the outcomes of his or her actions (to usually think before they act).

7. Respect for others - The extent to which the student demonstrates regard for the worth, rights, property, and feelings of others.

That qualitative study identified the broad attitudes, behaviors, and skills that were thematically associated with the academic survival of urban students as they traversed the difficult terrains of their schools and community. It is important to point out that there was no detailed analysis that precisely described how, when, or where these students acquired those characteristics. It should also be noted that those survival characteristics were viewed as relative, meaning only in comparison to their student peers. It is unknown how well developed the specific characteristics of those five urban students would measure in comparison to same age and grade peers from suburban and rural school districts.

\section{Analysis of the Academic Survival Skills}

To confirm and validate the findings of the 2005 inquiry of urban student academic survival skills, a follow-up quantitative study was completed in 2011. The second study included approximately 160 African-American students in grades 4-10 from a broad array of urban schools in northeast Ohio. To conduct this study, teachers completed a two-part survey that was designed to measure the correlation between the demonstration of academic survival skills and the grades students earned (Hampton 2014).

Part one of the survey was completed by teachers near the end of the first grading period. The first weeks of school gave the teachers time to become familiar with each student, develop daily classroom relationships, learn about their home environments, and observe their personal and academic behaviors. At the end of six weeks, the teachers were asked to rate their respective students in the areas of 1) Self-respect, 2) Command of Standard English, 3) Goal-setting ability, 4) Self-motivation, 5) Time management skills, 6) Consequence awareness, and 7) Respect for others. Each item received a rating of high, average, or low in terms of observed frequency.

Part two of the survey was completed by teachers after the first term final grades had been recorded. Although teachers had not been previously informed, they then were asked to provide the grade each respective student earned 
in the observed class. Through the statistical analysis, correlations between demonstrated academic survival skills and earned grades became quite clear. Students who were reported to display more of the academic survival skills during the observation period earned significantly higher grades than students who displayed fewer of those skills. For example, students who routinely demonstrated 4-7 of the skills typically earned grades of A-B, students who routinely demonstrated 3-5 of the skills typically earned grades of B-C, and students who routinely demonstrated 3 or fewer skills typically earned grades of $\mathrm{C}-\mathrm{F}$.

Pearson's Correlation Coefficient was used to model the linear correlation (dependence) between variables X (grades) and Y (academic survival skills). Linear Regression was used to model the relationship between a scalar dependent variable $\mathrm{X}$ (grade) and one or more of the explanatory variables $\mathrm{Y}$ (academic survival skills). Through multiple correlation analysis, fully two thirds $\left(R^{2}=.67\right)$ of the variance in grades was explained by the academic survival skills. This was an unusually high level of predictability and rivals the traditional educational predictors such as socio-economic status (SES) and prior achievement.

The academic survival skills variables were moderately to strongly inter-correlated, ranging from a low of .48 (the correlation between "goal-setting" and "self-respect") to a high of .84 ("goal-setting" and "self-motivation"). The academic survival skills were also moderately to strongly correlated with grades, "time management" having the highest correlation (.81) and "command of standard English" the lowest (.50) (Hampton 2014).

This study demonstrated significance far beyond the correlations between achievement and the display of academic survival skills. More important were the implications for a corollary curriculum in urban schools. Since the survival skills are strongly predictive of student achievement, then student achievement must also be strongly predictive of survival skills. Far too often, educators have attempted to improve urban student achievement simply by improving standardized test scores as evidence of growth. Frequently when standardized test scores are improved, they are the result of test-taking practice as opposed to improved learner traits, e.g., increased study time, greater homework completion, improved school attendance, and better classroom behavior. Any trustworthy documentation of significant improvements in urban student test-taking must also address the questions of "why" and "how" the students have changed. Urban schools should not first seek to improve standardized test scores, but instead, focus on improving the student traits that will result in higher standardized test scores.

\section{Incorporating Academic Survival Skills Into the Curriculum}

Over the past 30 years, much research has been conducted and many papers have been written which address the so-called "achievement gap." All of these works have generated important philosophies, practices, and programs that if implemented with fidelity could potentially lead to gains in urban student achievement. After all these years however, and although there are instances of promise, one is still hard-pressed to find reliable data illustrating nationwide significant growth and improvement in educational outcomes among African-American and Hispanic students. Sadly, there seems to be no current strategy or initiative capable of erasing the decades of problems that have plagued and stunted urban student growth.

Notwithstanding the need for increased school funding, better teacher preparation programs, and improved training for school principals, an equally urgent need should be to capitalize on what we have learned from students who have already found success in urban schools. Many urban students have demonstrated that there is less of an "achievement gap" and more of a gap in attitudes, behaviors, and skills that lead to academic achievement. Moreover, gaps in these areas could be immediately addressed because their development is not contingent upon school funding, additional faculty, or student socio-economic status.

The development of enhanced academic survival skills within the broad population of urban students would lead to more meaningful and long-lasting achievement, as well as the acquisition of tools for life-long learning and self-reliance. These attitudes, behaviors, and skills could be taught through the daily incorporation of their practice and held as expectations woven into the fabric and culture of all urban school activities. Through thoughtful planning from the earliest grades, guiding students to learn and develop the academic survival skills need not be viewed by teachers as a new curriculum or additional work, but rather as a more meaningful and creative way of providing instruction and to help students reach their full potential.

Urban educators must be aware that the acquisition and development of academic survival skills may not come quickly to all students. These skills will need to be encouraged and practiced every day, in every possible scenario, and under every possible set of circumstances. There is no shortcut to the internalization of attitudes, behaviors, and skills that are necessary for the long-term academic growth of African-American and Hispanic students. 
Some broad examples of how to teach and incorporate the development of academic survival skills into the urban school curriculum might include:

- Begin with highlighting the importance of self-respect and respect for others as necessary behaviors for the overall health of the learning environment. In every subject area and class, in every extra-curricular activity and club, in every assembly and social setting, there are natural opportunities for students to discuss and practice the importance of these behaviors. Such instances will help students begin to internalize how their personal behaviors either promote or infringe upon the opportunities of others to learn. Most importantly however, the faculty and administrators must always demonstrate respect to the students.

- To strengthen the command of Standard English, focus on the personal interests of students, then incorporate those areas into required reading and assignments. Increased reading is the most natural and efficient route to the mastery of language and grammar. Even if students choose not to use Standard English throughout the school day, the command should be at their disposal for use at their discretion.

- To develop goal-setting abilities, have students establish and write personal and academic short-term goals for each day. The goals could include ideas such as getting to school on time, getting a better grade on the next quiz, seeking additional help in weak subjects, completing homework before social activities, or receiving no discipline referrals during the week. Students should also establish and write personal and academic long-term goals such as having perfect attendance during the semester and obtaining higher final grades in specific subjects. Regardless of grade levels, all urban students should have written long-term post-high school goals to share with teachers and parents. Both short and long-term goals should be frequently reviewed with teachers and within small groups of friends to see if personal behaviors are aligned with the desired outcomes.

- Regarding student self-motivation, students will need to practice engaging in beneficial activities without continuous prompts to do so. Although self-motivation is based on an intrinsic system of rewards, teachers and administrators should also establish an external reward system for students who report the completion of important tasks without prompts. As students develop in this area, external rewards should be replaced with sincere praise and public or private recognition for their accomplishments.

- Teachers can help to sharpen students' time management skills by frequently referring to the short and long-term goals they established for themselves. The accomplishment of each goal requires a plan of action, and each plan of action must be positioned within a specific time frame. If students have set goals for daily homework completion, improved grades in specific subjects, no absences during the semester, or advanced placement status, then time and planning must be practiced and prioritized at the expense of other afterschool enjoyment.

- Teachers and administrators have always encouraged students to be aware of the consequences of their actions. The emphasis at this point should highlight how negative or unthoughtful behaviors will derail students from accomplishing their goals. Even students with the best academic survival skills will exhibit normal youthful behaviors which may not always be academically productive. The goal is not to produce students with perfect behavior, but students who consider the impact of their actions on their personal and academic goals.

\section{Summary}

There is a broad consensus that urban schools have been in decline for decades. As a result, we must accept that there will be no "silver bullets" or "magic pills" to quickly change the trajectory of its students. However, the good news is that change is possible. Economically disadvantaged students are not predestined to academic failure, and race is not indicative of school success. High achievement can become an expectation of all urban students if provided adequate opportunities, conditions, and support in developing self-reliance characteristics.

Previous endeavors to improve urban student achievement have rarely capitalized on the most critical factors; the students themselves. For most urban students, school success is not determined by innate intelligence or ability, but rather is the result of a strong desire to learn combined with appropriate attitudes, skills, and behaviors that allow for learning to take place. Academic achievement is not something that can be inserted into students, accomplished by punitive threats, or purchased for them. However, many urban students are certain to find academic success when they share more responsibility for their educational outcomes. The unfortunate truth is that students who are born 
into disadvantaged environments must simply do more for themselves and work harder in school than those who are not.

\section{References}

DeArmond, M., Patrick, D., Gross, B., Hernandez, J., Jochim, A, \& Lake, R. (2015). Measuring up: Educational improvement and opportunity in 50 cities. Center for Reinventing Public Education. Retrieved from crpe.org/publications/measuring-educational-improvement-and-opportunity-50-cities

Hampton, F. M. (2008). The seven secrets of successful inner-city school students. Retrieved from www.ascd.org/ascd-express/vol3/314-hampton.aspx

Hampton, F. M. (2014). The seven secrets of successful urban school students: The evidence continues to grow. Education and Urban Society. Retrieved http://eus.sagepub.com/content/early/2014/05/03/0013124514533990

Hudley, C. (2013). Education and urban schools. The SES Indicator, 6(2). Retrieved from apa.org/pi/ses/resources/indicator/2013/05/urban-schools

\section{Copyrights}

Copyright for this article is retained by the author(s), with first publication rights granted to the journal.

This is an open-access article distributed under the terms and conditions of the Creative Commons Attribution license (http://creativecommons.org/licenses/by/4.0/). 